\title{
CARTAS DE OFERTA \\ DE “QUARTEL” EM TUPI \\ DE LIDERANÇAS \\ POTIGUARAS (1645)
}

\author{
Cândida BARROS (DD \\ Museu Emílio Goeldi (MPEG) \\ Ruth MONSERRAT ID \\ Universidade Federal do Rio de Janeiro (UFRJ)
}

Open access

EDITORES

- Miguel Oliveira, Jr. (UFAL)

- René Almeida (UFS)

AVALIADORES

- Beatriz Christino (UFRJ)

- Jaqueline Peixoto (UFRJ)

SOBRE OS AUTORAS

- Cândida Barros

Conceptualização, Investigação.

- Ruth Monserrat

Análise Formal, Investigação.

DATAS

- Recebido: 03/08/2021

- Aceito: 03/08/2021

- Publicado: 11/09/2021

\section{COMO CITAR}

BARROS, Cândida; MONSERRAT, Ruth (2021). Cartas de oferta de "quartel" em tupi de lideranças Potiguara (1645) Cadernos de Linguística, v. 2, n. 4 , e447.

\section{RESUMO}

O trabalho apresenta os resultados preliminares de uma pesquisa sobre seis cartas em tupi de lideranças potiguaras. Elas foram escritas em 1645 durante a guerra luso-holandesa. A hipótese da pesquisa é que os chefes militares potiguaras pró-portugueses se apropriaram da forma de escrita do ato de rendição militar da guerra europeia (que chamaremos de carta de oferta de quartel), incluindo, porém, marcas discursivas próprias da oratória indígena, como o uso da interpelação através de termos de parentesco, entre outros recursos linguísticos. A transcrição paleográfica, a segmentação linguística e a tradução preliminar para o português do corpus epistolar são atividades já realizadas. Na presente versão do projeto de pesquisa os objetivos são inventariar no corpus potiguara o léxico do campo semântico da guerra e da rendição, as formas pronominais de primeira pessoa e os termos de parentesco. A hipótese é que por esses recursos lexicais e gramaticais em tupi se pode observar o caráter híbrido das cartas, que se aproximaria da oratória tupi de chefia. No trabalho são exemplificados tais traços com trechos de uma das cartas do líder potiguara Filipe Camarão (1601-1648), por ser o autor menos traduzido para o português. 


\section{ABSTRACT}

This work presents the preliminary results of a research whose corpus is constituted of six letters of Potiguara leaders in Tupi language. The letters were written in 1645 during the Luso-Dutch War. The research departs from the hypothesis that the pro-Portuguese Potiguara military leaders have assumed a formality, typical of the European war, which is the written offer of surrender with a promise of good treatment to the defeated, incorporating in these texts, discursive features of Tupi oratory. The paleographic transcription, the linguistic segmentation and the preliminary translation of the epistolary corpus into the Portuguese language are activities already carried out. In this version, the objectives are to inventory, within the Potiguara corpus, the lexicon of the semantic field of war and surrender, the pronominal forms and the terms of kinship. The hypothesis is that by using these lexical and grammatical resources in Tupi, it is possible to observe the hybrid character of these letters, as they approach the Tupi oratory of leadership. In this study, we exemplify these traits with excerpts from the letter of the Potiguara leader Filipe Camarão (1601-1648), as he is the least translated author among those who wrote letters of "quartel" offer.

\section{PALAVRAS-CHAVE}

Índios Potiguaras; Cartas de Oferta de Quartel; Língua Tupi; Guerra Luso-Holandesa.

\section{KEYWORDS}

Potiguara Indians; Letters of "Quartel” Offer; Tupi Language; Luso-Dutch War. 


\section{INTRODUÇÃO}

A ativa participação indígena na guerra luso-holandesa no Nordeste está testemunhada em seis cartas em tupi escritas por líderes potiguaras pró-portugueses entre agosto e outubro de 1645 e endereçadas a seus parentes pró-holandeses. As datas remetem para a conjuntura da Insurreição Pernambucana (1645-1654), durante a qual houve o recrudescimento militar do conflito luso-holandês no Nordeste, depois de um período de relativa paz entre 1638 e 1645 (MELLO, 2010, p.162; MIRANDA, 2020, p.34).

A hipótese da pesquisa, intitulada "Correspondência potiguara de 1645 como gênero discursivo híbrido em tupi”, é que essas seis cartas trocadas entre os chefes indígenas em lados opostos da guerra colonial apropriaram-se de elementos de duas práticas discursivas na interação por escrito em tupi. Elas seguem a formalidade de escrita do ato de rendição militar da guerra europeia (que chamaremos de carta de oferta de quartel), incluindo, porém, marcas discursivas próprias da oratória tupi, como o uso da interpelação através de termos de parentesco, entre outros recursos linguísticos.

A pesquisa tem caráter interdisciplinar, reunindo o historiador Bruno Miranda (UFRPE), que será o responsável pela contextualização histórica da guerra lusoholandesa, e as linguistas Ruth Monserrat (UFRJ) (especialista em línguas da família tupi e tradutora das cartas potiguara) e Cândida Barros (MPEG) (especialista em sociolinguística da época colonial).

O ponto de partida da pesquisa é a caracterização da correspondência potiguara como cartas de oferta de quartel. Um dos sentidos militares do termo "quartel" no dicionário português-latim de Raphael Bluteau é "He o bom trato, que os vencedores prometem aos vencidos, que se rendem, \& largaõ as armas" (BLUTEAU, 1712, v.7, p.21). Na forma de "quartier" (quartel), o termo aparece algumas vezes na tradução das cartas em tupi para o holandês em 1646 (EDWARD, 1646 apud SOUTO MAIOR, 1912/1913), e na forma de "coartel" (empréstimo do português) por Filipe Camarão - um dos principais líderes indígenas próportugueses - ao escrever para os destinatários potiguaras aliados dos holandeses (CAMARÃO, F.19 de agosto de 1645).

A caracterização das cartas como tendo a função de oferta de quartel permite ao historiador contextualizar a prática das negociações de rendição na guerra, as alianças e conflitos indígenas, e às linguistas enfatizar, na etapa atual do trabalho, o léxico usado para convencimento de rendição.

A função comunicativa da carta de oferta de "quartel", ou seja, de "bom trato do vencedor ao vencido" supõe, em termos discursivos, que o remetente precisa convencer o destinatário de sua posição de vencedor, e que o destinatário precisa confiar na oferta de bom trato aos que desistirem da guerra. As cartas potiguaras não teriam, portanto, uma 
função informativa, no sentido de que o remetente estivesse comunicando ao remetente algo que este desconhecesse.

\section{OBJETIVOS}

Os objetivos do trabalho são apresentar os resultados preliminares da pesquisa sobre as cartas potiguaras em tupi, cujos passos iniciais consistiram na transcrição paleográfica conservadora das cartas, em sua segmentação morfológica, quando necessária para o melhor entendimento do leitor não especializado, e tradução preliminar para o português, incluindo ainda, na presente etapa, o levantamento dos seguintes aspectos:

a) léxico do campo semântico da guerra e da rendição recorrente no corpus potiguara (canhem, nhe-meeng, coartel, etc);

b) formas pronominais dêiticas de primeira pessoa do plural - nós inclusivo ( $n h a n d e$ ) e nós exclusivo (ore);

c) termos de parentesco, organizados pelos seguintes critérios: i) vocativo -gui ,); ii) autoidentificação do remetente na relação com o destinatário e iii) referência a uma terceira pessoa pelo remetente. Essa descrição dos dados foi baseada na proposta sociolinguística de Asif Agha (2007) de analisar os termos de parentesco como configuradores de relações interpessoais.

Tal enfoque possibilitará uma reflexão mais aprofundada sobre o mundo indígena potiguara refletido nas cartas, nas quais transparece a superposição de poderes e de culturas nos espaços coloniais do século XVII.

\section{CORPUS POTIGUARA EPISTOLAR EM TUPI}

Na segunda metade do século XIX, um conjunto de cartas em tupi escritas por índios potiguaras entre 1645 e 1646 foram encontradas no Arquivo de Haia por José Higino Duarte Pereira (1886), responsável também pela primeira transcrição paleográfica para o acervo do Instituto Histórico e Arqueológico Pernambucano. Devemos ao historiador e geógrafo 
Theodoro Sampaio, no artigo "Cartas tupi dos Camarões" (1906), a tradução para o português e o primeiro estudo dessa documentação tupi.

O levantamento dos autores das seis cartas e de seus respectivos destinatários é apresentado na Tabela 1 abaixo:

\begin{tabular}{|l|l|}
\hline Remetentes & Datas e destinatários \\
\hline Capitão mór Filipe Camarão (1601-1648) & $\begin{array}{l}\text { Carta de } 19 \text { de agosto de } 1645 \text { para vários destinatários } \\
\text { não nomeados } \\
\text { Carta de } 4 \text { de outubro de } 1645 \text { para Antônio Paraupaba } \\
\text { Carta de } 4 \text { de outubro de } 1645 \text { para Pedro Poti }\end{array}$ \\
\hline $\begin{array}{l}\text { Capitão Simão Soares } \\
\text { Parayba/lagoarari }\end{array}$ & $\begin{array}{l}\text { Pós-escrito em carta de Filipe Camarão de } 19 \text { de agosto de } 1645 \\
\text { para destinatários não nomeados }\end{array}$ \\
\hline Capitão Diogo da Costa & Carta de 17 de outubro de 1645 para Pedro Poti \\
\hline Sargento Diogo Pinheiro Camarão & $\begin{array}{l}\text { Carta de } 21 \text { de outubro de } 1645 \text { para quatro capitães } \\
\text { Carta de } 21 \text { de outubro de } 1645 \text { para Pedro Poti }\end{array}$ \\
\hline
\end{tabular}

Tabela 1. Remetentes e destinatários.

Essas cartas foram escritas num intervalo de três meses (agosto a outubro de 1645), envolvendo autores e destinatários diferentes, cada um em distintos locais e tempos. Apesar da dispersão temporal e geográfica das cartas quando de sua apreensão pela Companhia de Comércio das Índias Ocidentais - principal instituição que governava a ação holandesa no Nordeste -, elas foram agrupadas e enviadas para a Holanda em conjunto numeradas de 1 a 6 -, para serem traduzidas pelo ex-pastor em Pernambuco Johannes Edward, que escreveu "todas [cartas] tractam do mesmo assumpto, isto é, que os índios se devem passar para os portugueses" ( EDWARD, 1646 apud SOUTO MAIOR, 1912, p. 402).

A esse corpus em tupi se agregam mais duas cartas de autores potiguaras, cujas versões em tupi não foram preservadas, e das quais se conhece apenas a tradução em holandês. Uma delas é de Pedro Poti, potiguara pró-holandês, que escreve para Filipe Camarão em 31 de outubro de 1645 (SOUTO MAIOR, 1912/1913). A outra foi escrita por Filipe Camarão em 1646 para vários destinatários pró-holandeses.

Depois da primeira tradução para o português das seis cartas em tupi feita por Theodoro Sampaio (1906), outras mais atualizadas foram publicadas: a do Capitão Diogo da Costa (CERNO; OBERMEIER, 2013) e a do Sargento Diogo Pinheiro Camarão (NAVARRO, 1998/ CERNO; OBERMEIER, 2013). Entre as cartas dos autores potiguaras, as de Filipe Camarão são as menos conhecidas, motivo pelo qual, para apresentar os procedimentos da pesquisa e seus resultados parciais, serão privilegiados exemplos com trechos de suas cartas.

Em relação ao corpus epistolar potiguara, cada uma das seis cartas recebeu uma transcrição paleográfica conservadora, uma segmentação de caráter morfológico e 
sintático e uma tradução preliminar para o português. Essas etapas foram frequentemente invertidas, quando problemas na segmentação nos fizeram retornar, por exemplo, ao nível da transcrição paleográfica. A segmentação está baseada nas convenções gráficas da língua tupi usadas pelos jesuítas nos séculos XVI e XVII (baseadas na gramática de Anchieta ([1595]1990).

Os negritos ao longo do trabalho foram incluídos pelas autoras para enfatizar certas passagens e termos específicos. Os números entre parênteses se referem às passagens da carta de Filipe Camarão de 19 de agosto de 1645.

\section{CARTAS DE OFERTA DE QUARTEL EM PORTUGUÊS}

Quartel. He o bom trato, que os vencedores prometem aos vencidos, que se rendem, \& largaõ as armas. Este modo de falar procede, de que os Hollandezes, \& os Castellanos convierã̃ em que o resgate de hum Official, ou Soldado, se tomaria de hũ a quarta parte da sua paga [...]

(BLUTEAU, 1712, v.7, p.21).

Com a intensificação das ações militares durante a Insurreição Pernambucana, houve inúmeros casos de negociações por escrito sobre rendição na guerra, tanto de chefes portugueses para holandeses como de holandeses para portugueses, índios e negros. Exemplificamos essa formalidade militar com uma passagem de oferta de quartel em português escrita em 1648 pelos holandeses oferecendo perdão "a q. q. pessoa de qq nação, estado, e condição", ou seja, a portugueses, indígenas e negros que tivessem participado de ações militares. Várias cópias desses documentos eram deixadas pelos caminhos, estipulando o prazo de seis dias para o aceite.

\footnotetext{
Por ordem particular, que tivemos mandada à Nos, pelos Poderosos Estados Geraes, Sua Alteza - Principe de Orange, e a Geral Outrogada Companhia Occidental, a Nós remetida com o poder já chegado [...] que a q. q. pessoa de qq nação, estado, e condição, q seja, outroguemos em seu nome perdão geral de rebelião, desobediência, conspiração, q.q. outro delito, ainda q seja hua e muitas vezes cometido. [...] sobre esta declaração esperamos seis dias pela resposta de VV SS Feita em o nosso concelho do Arrecife em dous de Abril de 1648 João Bolestrater Henrique Hamel Pedro Bakes Pelo secretário João Balbekes (Carta dos holandeses, 1648).
}

A carta acima recebeu três respostas negativas. Uma delas foi assinada por João Fernandes Vieira e André Vidal dos Negreiros, representando os portugueses; Henrique Dias fez o mesmo como "Governador dos Negros" e Filipe Camarão o fez como "Governador dos Índios". Segue um trecho da resposta deste último:

Tudo quanto VV pertendem conquistar com folhas de papel, lhes havemos defender com as das espadas; e para quem as sabe empunhar, como sabem os meus soldados, vem a ser rediculos seus perdoens, e suas promessas. Ninguem quer dever o mesmo, que pode cobrar. Estes seus papeis achados, como perdidos, mais tem de perdidos do q tem de achado:.[ ...] D Antônio Felipe Camarão, Governador dos Índios (Carta dos holandeses, 1648). 
Mais adiante ficará patente que Filipe Camarão nunca faz uso do título militarpolítico de "Governador dos Índios" em sua correspondência para os potiguaras aliados dos holandeses.

\section{OFERTA DE QUARTEL EM TUPI ANALISADA ATRAVÉS DE LÉXICO ESPECÍFICO, PRONOMES E TERMOS DE PARENTESCO}

A expressão carta de oferta de quartel não é encontrada como tal nas fontes potiguaras em tupi. Aliás, a própria referência à "carta" é ambígua: dois termos são utilizados para isso, "nheenga", que significa fala, língua, palavras, e papera, empréstimo do português, que representa mais propriamente a carta como suporte material.

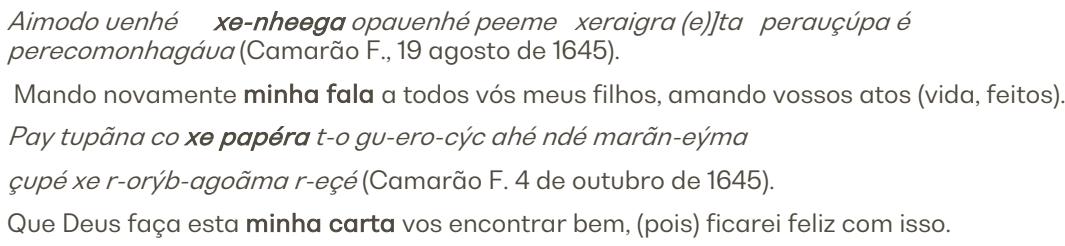

É preciso examinar com mais detalhe o uso das duas palavras, que aparentemente se intercambiam sem mudança de significado.

\subsection{LÉXICO DO CAMPO SEMÂNTICO DA GUERRA E DA RENDIÇÃO}

Certos termos da língua tupi são recorrentes nas seis cartas, conformando um campo semântico de guerra e de rendição, que constitui a base para oferecer um bom trato aos vencidos caso eles se rendam. Listamos na Tabela 2 alguns desses termos.

\begin{tabular}{|l|l|}
\hline 'guran & $\begin{array}{l}\text { (6) Çaçig-ete ã ixe-ve mae aiba pe-remimonhag-oéra reçe co marana porauçúba } \\
\text { reigma. } \\
\text { Me entristecem[doem] muito as coisas más que fizestes nesta guerra miserável } \\
\text { [sem amor]. }\end{array}$ \\
\hline $\begin{array}{l}\text { canhem } \\
\text { 'perder-se, fugir, destruir-se' }\end{array}$ & $\begin{array}{l}\text { (9) apiabaiba pitibo-sara opacatu icanhemi cueçe a a } \\
\text { os homens maus (holandeses) ajudadores todos perderam antes }\end{array}$ \\
\hline
\end{tabular}




\begin{tabular}{|c|c|}
\hline $\begin{array}{l}\text { sem } \\
\text { 'sair' }\end{array}$ & $\begin{array}{l}\text { (17) Emonanamo pe-pua(r) çeçe yxui pe-çema } \\
\text { Então liguem isso a vossa saída }\end{array}$ \\
\hline $\begin{array}{l}\text { pepigr } \\
\text { 'mudar de lado' } \\
\text { (torcer, virar) }\end{array}$ & $\begin{array}{l}\text { (14) Pe-imoag-ime apiabaiba ore-çui pepig çerã, ixupẽ nho ã } \\
\text { coarte/ nhe-meégi } \\
\text { vocês imaginaram que talvez os homens maus } \\
\text { (os holandeses) nos torceriam [e] nos renderíamos ao quartel deles }\end{array}$ \\
\hline $\begin{array}{l}\text { yerobiar } \\
\text { 'confiar' }\end{array}$ & $\begin{array}{l}\text { (24) O-gubixaba o-guca[r] pe-ierobiar-eigma } \\
\text { (Vosso?) próprio chefe mandou vocês não confiarem }\end{array}$ \\
\hline $\begin{array}{l}\text { meeng perdão geral } \\
\text { 'dar perdão geral' }\end{array}$ & $\begin{array}{l}\text { (20) pe-tẽ-me pe-ie-agua-bo pe-goacemo xeçuia-imee-gatu ipo } \\
\text { ne perdaó geral peeme ne pe-remi-mo[nhaga-pira-mo] } \\
\text { eia!se vocês se injuriando(arrependendo) chegam a mim, eu talvez vos dê perdão } \\
\text { geral pelo que vocês fizeram }\end{array}$ \\
\hline $\begin{array}{l}\text { nhemeeng coartel } \\
\text { 'dar' / 'entregar-se' (dar-se) }\end{array}$ & $\begin{array}{l}\text { (8) opacatu icanhemi oreçui nonhemeegagaj agoa çupe cuar [rasura] } \\
\text { todos fugiram (se afastaram, perderam) de nós para não se render a cuar } \\
\text { [quartel?] } \\
\text { (14) Pe-imoag-ime maramonhaga-pe ore-guaçẽbaba çupe } \\
\text { coartel nhe-meega, Pe-imoag-ime apiabaiba ore-çui pepig çerã, ixupẽ nho ã } \\
\text { coartel nhe-meégi } \\
\text { porque vocês imaginaram que na nossa chegada da guerra nos renderíamos ao } \\
\text { quartel, porque vocês imaginaram que talvez os homens maus (holandeses) nos } \\
\text { torceriam [e] nos renderíamos ao quartel deles }\end{array}$ \\
\hline
\end{tabular}

Tabela 2. Léxico da guerra e da rendição.

O empréstimo português coarte/foi usado três vezes na carta de 19 de agosto de Filipe Camarão, sendo que na terceira ocorrência o termo está danificado na linha em questão, trazendo problemas de transcrição.

\subsection{PRONOMES DE PRIMEIRA PESSOA DO PLURAL INCLUSIVO E EXCLUSIVO}

A perspectiva pragmática dos pronomes de primeira pessoa do plural inclusivo e exclusivo em tupi permite interpretar a rede de interação estabelecida entre destinatário e remetente pelas cartas. A gramática de Anchieta ([1595]1990) assim apresenta a diferença entre eles:

\footnotetext{
"Orê exclue a segunda pessoa com que falamos daquele ato" [...] exemplo orê oroçô, nos imos e tu não.

"Yandê inclui a segunda pessoa [...] nos imos, \& tu também (ANCHIETA, 1990).
} 
Na carta de 19 de agosto de Filipe Camarão há o emprego das duas formas, com uma distribuição discursiva bem definida. Quando Filipe reclama das ações militares dos destinatários contra seu grupo, ele se distingue deles usando ore, e quando quer persuadilos a se render, incorpora-os através do uso de nhande, como mostra a tabela 3 abaixo.

\begin{tabular}{|c|c|}
\hline Primeira pessoa plural exclusivo: ore & Primeira pessoa plural inclusivo: nhande \\
\hline $\begin{array}{l}\text { (7) Maranamo co igbigpór-eté-ramo pe-reco-ríme ã } \\
\text { maramonhaga pe ore-guaçém-á-ba n-açauçubár-ipí- } \\
\text { ramo ruã cecou. } \\
\text { Por que vocês, vivendo nesta terra, estão lutando } \\
\text { contra nós (exclusivo) sem misericórdia? }\end{array}$ & $\begin{array}{l}\text { (3)Nicatúy-nhe co nhade retáma pupe-nhe pe-reco } \\
\text { pupe pe-canhem-ete-catu-ábo xeçuj christaõ ramo pe- } \\
\text { reco pupe (Filipe, } 19 \text { de agosto de } 1645 \text { ) } \\
\text { Não é bom que nesta nossa (inclusivo) terra em que } \\
\text { viveis estejais fugindo de mim, quando sois cristãos. }\end{array}$ \\
\hline $\begin{array}{l}\text { (8) [..] opacatu icanhemi oreçuj nonhemeegagaj agoa } \\
\text { çupe cuartel } \\
\text { todos fugiram (se afastaram, perderam) de nós } \\
\text { (exclusivo) para não se render ao quartel }\end{array}$ & $\begin{array}{l}\text { Emonãnamo t-ereçoçẽ apiabaíba çuí, nhãde anáma } \\
\text { le]ta(Filipe, } 4 \text { de outubro de 1645) } \\
\text { Por isso, afasta-te dos homens maus (holandeses) e } \\
\text { trazei os nossos (inclusivos) parentes }\end{array}$ \\
\hline
\end{tabular}

Tabela 3. Usos de primeira pessoa do plural inclusivo e exclusivo.

Os termos parente (anama) e terra /nação (retama) são usados com a forma inclusiva, e os trechos contendo os infortúnios sofridos pelo grupo de Filipe Camarão fazem uso da forma exclusiva.

\subsection{USO DE TERMOS DE PARENTESCO}

Era habitual entre os tupinambás, segundo o frei francês Claude d'Abbeville (?-1632) no século XVII, interpelarem-se por meio de termos de parentesco:

\footnotetext{
É para admirar, que sendo os Indios Tupinambas, apenas guiados pela própria natureza, embora seja ella a mais estragada, que é possível conservem entre si amor reciproco tão condial como fraternal, pelo que costumam a dar uns aos outros o nome de Pai, mãe, irmãozinho, tio, sobrinho, ou primo, como se fossem todos da mesma família ou parentesco (D'Abbeville, 1874, p. 331).
}

Esse hábito verbal se manifesta nas cartas potiguaras. Filipe Camarão faz uso dos termos de parentesco como estratégia discursiva para atingir o efeito político de atração do destinatário para o seu lado. Um dos mais profícuos dentre eles para instaurar relações intersociais é o de pai (tuba). Em uma lista de termos de parentesco "uteis ao confessor" no catecismo jesuítico de Antônio Araújo (1618), o termo significava tanto o pai como os tios e os primos paternos, e estes eram diferenciados linguisticamente do tio e primo materno (“Tuba. Pay natural, ou tio, ou primo do pay. Vtriusques sexus” ARAÚJO, 1618, p.116r).

No exemplo abaixo na carta de agosto de 1645, o capitão Filipe se apresenta na assinatura da carta como pai dos destinatários:

\footnotetext{
Opabenhé pe rúba Capp tam mor Camaraõ (CAMARÃO, F. 4 de outubro de 1645)

O pai de todos vós Capitão mor Camarão.
} 
Da mesma forma, interpela como filhos os destinatários coletivos da carta:

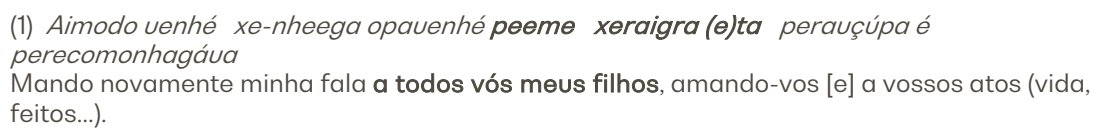

A par disso, Camarão usa a partícula ete (intensificador tupi incorporado ainda no século XVI ao uso de 'pai') para reforçar seu status político frente aos potiguaras, autonomeando-se seu pai legítimo (tubaete), como se pode ver na mesma carta de 19 agosto de 1645:

(2) Aimodo venhe peeme maránamo opavenhé perub-eté-ramo gui-tecóbo é, pe-recó catu canhema çuj.

Mando-vos novamente por ser opai verdadeiro de todos vós, [para livrar-vos] de vossa perdição.

O emprego de ete para parentesco é referido por Anchieta como tendo sido criado pelos antigos missionários:

\begin{abstract}
O nome temirecô etê, sc, uxor vera, creio que o tomaram dos Padres, que lhes queriam dar a entender a perpetuidade do matrimônio, e qual é a mulher legítima, porque deste vocábulo etê, que quer dizer legíyimo, usam eles nas coisas naturais da sua terra, e assim a seu vinho chamam cãoy etê [..] Mas na matéria de parentesco nunca usam deste vocábulo etê, [...] para declararem quem é seu pai, ou filho verdadeiro, etc, nunca dizem xerubetê, meu pai verdadeiro, senão xeruba xemonhangára meu pai qui me genuit (ANCHIETA, 1867, p. 258-259).
\end{abstract}

Tuba-ete ficou cristalizado nos diálogos de doutrina como referência exclusiva a Deus como pai verdadeiro, diferente do pai biológico.

\footnotetext{
R[esposta]. Ýbâkypé Tupã, xe Rubete cecoû-ma açó xé Rúba pŷri, xeretametépé má. No céu está Deus, meu Pai verdadeiro, eu irei para junto de meu Pai, para minha verdadeira pátria (ANCHIETA, 1988).
}

Assim, a extrapolação por Filipe Camarão do uso tupi de tubete - fixado no discurso jesuítico para a referência a Deus Pai como "detentor do poder cristão máximo", aponta para sua apresentação como “detentor do poder político máximo” na guerra.

No final das cartas, todos os autores potiguaras assinam e são referidos por seus cargos militares, porém há um recorrente uso de termos de parentesco. Como foi dito, Filipe Camarão nunca faz uso do título de Governador dos Índios ao se apresentar. Em suma, termos de parentesco são usados na construção de alianças políticas entre adversários que estão em lados diferentes do mundo colonial (pró-portugueses ou pró-holandeses). 


\section{A TÍTULO DE CONCLUSÃO}

Os resultados preliminares reforçam a hipótese da apropriação, pela elite potiguara, do gênero discursivo da oferta de quartel próprio da formalidade da guerra luso-holandesa, com a incorporação nas cartas de elementos da oratória indígena (nheenga), como o emprego dos termos de parentesco, o jogo de alternância nós inclusivo e nós exclusivo, o uso peculiar do léxico da guerra. O neologismo jesuítico tubete em tupi foi apropriado por Filipe Camarão para expressar seu poder político máximo.

A hipótese das cartas potiguaras como expressão de um novo gênero textual potiguara híbrido em tupi requer, numa próxima etapa da pesquisa, uma análise comparativa dos pronomes dêiticos nós inclusivo e exclusivo (ore $\mathrm{x}$ nhande) em todas as seis cartas, para confirmar as modalidades do seu uso.

Como continuidade, a pesquisa tem previsto para o segundo semestre de 2021 o diálogo com o historiador Bruno Miranda para aprofundar de forma interdisciplinar o tema das alianças e conflitos indígenas, o que permitirá contextualizar elementos discursivos da interação entre destinatário e remetente no nível macro (contexto sócio-histórico) e no nível micro (recursos linguísticos discursivos).

\section{AGRADECIMENTOS}

Nossos agradecimentos a Bartira Barbosa (UFPE) pela nossa introdução ao universo das cartas em tupi, a Gabriel Prudente pela transcrição diplomática preliminar das seis cartas e a Bruno Miranda (UFRPE), parceiro atual deste estudo. A pesquisa recebeu apoio do CNPq para o seu desenvolvimento.

\section{REFERÊNCIAS}

ABBEVILLE, C. História da missão dos padres capuchinhos na ilha do Maranhão e suas circumvisinhaças. São Luis: Typographia Frias, 1874. http://www2.senado.leg.br/bdsf/handle/id/221724. Consultado em 17/06/2021.

AGHA, A. Language and social relations. Studies in the Social and Cultural Foundations of Language. Cambridge: Cambridge University Press. 2007.

Anchieta, J. Diálogo da fé: Introdução histórico-literária e notas de Armando Cardoso. Obras Completas, Vol.10. São Paulo, SP: Edições Loyola, 1988.

ANCHIETA, J. Informação dos casamentos dos índios do Brasil. Revista do Instituto Historico e Geographico Brasileiro. Rio de Janeiro, t. 8, p. 254-262, 1867. http://www.etnolinguistica.org/biblio:anchieta-1846-casamentos. Consultado em 11/06/2021.

ANCHIETA, J. Artes de gramática da língua mais usada na Costa do Brasil. São Paulo: Edições Loyola, [1595] 1990. 
ARAÚJO, A. Catecismo na língua brasílica. (fac-símile da edição de 1618). Rio de Janeiro: Olímpica. 1952.

AYROSA, P. Vocabulário na língua brasílica. Manuscrito português-tupi do século XVII. São Paulo: Departamento de Cultura. 1938. _http://www.etnolinguistica.org/biblio:anonimo-1938-vocabulario. Consultado em 11/06/2021.

BARBOSA, A. L. Pequeno vocabulário tupi-português. Rio de Janeiro: Livraria São José. 1967.

BLUTEAU, R. Vocabulário Português e Latino. Coimbra : Collegio das Artes da Companhia de Jesu : Lisboa : Officina de Pascoal da Sylva, 1712-1728. https://digital.bbm.usp.br/handle/bbm/5412. Consultado em 11/06/2021.

CAMARÃO. F. Carta em tupi para Antônio Paraupaba. 4 de outubro de 1645. Arquivo Nacional de Haia. NLHaNA_OWIC 1.05.01.01, inv. nr. 62, doc. 55.

CAMARÃO. F. Carta para Pedro Poti. 4 de outubro de 1645. Arquivo Nacional de Haia. NL-HaNA_OWIC 1.05.01.01, inv. nr. 62, doc. 53 .

CAMARÃO. F. Carta em tupi para destinatários não nomeados. 19 de agosto de 1645. Arquivo Nacional de Haia. HaNA_OWIC 1.05.01.01, inv. nr. 62, doc. 57

CAMARÃO, D. P. Carta em tupi para Pedro Poti. 21 de outubro de 1645. Arquivo Nacional de Haia. HaNA_OWIC 1.05.01.01, inv. nr. 62, doc. 52.

CAMARÃO, D. P. Carta para 4 capitães. 21 de outubro de 1645. Arquivo Nacional de Haia. HaNA_OWIC 1.05.01.01, inv. nr. 62, doc. 54 .

COSTA, D. Carta para Pedro Poti. 17 de outubro de 1645. Arquivo Nacional de Haia.

Carta dos holandeses, oferecendo o perdão a todos os rebeldes que se renderem a seu domínio e respostas dos brasileiros, João Fernandes Vieira, André Vidal de Negreiros, Antônio Felipe Camarão e Henrique Dias, em nome de todos os defensores do Brasil na luta contra a Holanda. Biblioteca Nacional do Rio de Janeiro (Manuscrito. cópia). 1648.

CERNO, L., OBERMEIER, F. Cartas de indígenas potiguaras de las Guerras Holandesas en el Brasil (1645-1646). Corpus. Arquivos virtuales de la Alteridade americana, Buenos Aires, v.3, n.1, 2013.

https://journals.openedition.org/corpusarchivos/368. Consultado em 11/06/2021.

MELLO, E. C. O Brasil Holandês. São Paulo: Companhia das Letras. 2010.

MIRANDA, B. Fontes e abordagens recentes para a História das Capitanias do Norte: um guia de pesquisa sobre o tempo dos holandeses (1630-1654). História Unicap, v. 7, p. 33-55, 2020.

http://www.unicap.br/ojs/index.php/historia/article/view/1657. Consultado em 11/06/2021.

MONSERRAT, R. \& al. Um escrito tupi do capitão Simão Soares Parayba (1645). Corpus. Archivos virtuales de la alteridad americana, vol. 10, n.2, 2020.

NAVARRO, E. A. Método Moderno do Tupi Antigo: a língua do Brasil dos primeiros séculos. Petrópolis: Editora Vozes. 1998.

PEREIRA, J. H.D. Trechos do relatório que leu o Dr. José Higino Duarte Pereira de volta de sua excursão à Holanda para fazer aquisição de documentos relativos às lutas com os holandeses no Brasil. Revista do Instituto Histórico e Geográfico Brasileiro. 49, v. 73, pt. 2, p. 183-243, 1886.

SAMPAIO, T. Cartas tupis dos Camarões. Revista do Instituto Archeologico e Geographico Pernambucano, Recife, vol.12, n. 68, 1906. http://www.etnolinguistica.org/biblio:sampaio-1906-cartas. Consultado em 11/06/2021.

SOUTO MAIOR, P. Dous índios notáveis e parentes próximos Pedro Poty e Philippe Camarão. Revista do Instituto Histórico Arqueológico Pernambucano, Recife, n15. 1912

http://portal.ceara.pro.br/index.php?option=com_content\&view=article\&id=33686\&catid=464\&ltemid=101. Consultado em 11/06/2021.

SOUTO MAIOR, P. Fastos Pernambucanos. Revista do Instituto Histórico e Geográfico Brasileiro, Rio de Janeiro, n. 75. 1913. 